\section{¿Un nuevo malestar en la cultura? Variaciones sobre la crisis de la modernidad}

\section{José Enrique Rodríguez Ibáñez CIS. Madrid. 1999}

Pocos son los pensadores que se atreven a sondear conceptualmente las profundidades de la crisis de la conciencia moderna, pues el coeficiente ansiógeno se acrecienta al constatar la desaparición de las coordenadas seguras que la definían. La perspicacia de autores como Weber, Freud y Mannheim, estriba en el hecho de haber anticipado el diagnóstico del descentramiento de la modernidad. Rememoremos por un momento a este último en ese umbral de lucidez que es «Ideología y utopía»: «Es un ver dadero imperativo del momento aprovechar la actual luz crepuscular, que revela la relatividad de las cosas y de las posiciones políticas, para com prender de una vez por todas que la estructura de significaciones que dan forma a nuestro mundo son bambalinas cambiantes históricamente relativas, dentro de las cuales se despliega el devenir humano. En un momento histórico tal,... debemos controlar la situación mediante una aprehensión científica».

En la estela de esa dinastía de pensamiento, presta a encarar científicamente la actual luz crepuscular, José Enrique Rodríguez Ibáñez aborda el descentramiento de nuestras sociedades en crisis de la modernidad, definiéndolo a la manera freudiana como nuevo malestar en la cultura. Toda conciencia del malestar define una época y, al hacerlo, encarna, como diría J. L. Aranguren (a cuya memoria está dedicado el libro) una pluralidad de talantes diversos, desde el abatimiento ante la frustración de los ideales de la razón, a la manera de Habermas; a las que desvelan una heteróclita gama de regocijos ante el desfondamiento de los metarrelatos ilustrados mostrados como severos inquisidores (Foucault, Lyotard, Vattimo, Baudrillard, Denzin). Lejos del peligro que señalara Adorno al comienzo de Minima Moralia: quedar apresados en el paroxismo y reproducir, así, la dolencia que es el origen de nuestro malestar, el talante de Rodríguez Ibáñez en sus «variaciones sobre la crisis de la modernidad» se halla alejado tanto del vehemente tardoromanticismo, como de la patología denunciada por Sloterdijk: el cinismo de la autocomplacencia ilustrada, dispuesta siempre a enmascarar sus costes, Rodríguez Ibáñez ha rescatado de Rorty el ironismo como terapia frente a las malas compresiones del presente. Así, la distancia irónica adoptada ante el frustrado canon de la modernidad, permite la investigación en términos sociológicos de la actual recidiva de su crisis, haciendo posible su estudio en otro tono (menos emotivo y más reflexivo) y con otra metodología (más discursiva y menos positivista).

Compendio de una serie de ensayos escritos en los últimos años, este libro completa la panorámica del autor, revisados y reelaborados para esta publicación, reflejando las afinidades electivas que han jalonado su trayectoria intelectual. La variedad temática de su arquitectura está vertebrada en torno a un objetivo central «buscar salida conceptual a las perplejidades del fin de milenio», que a su vez se articula en un doble eje. Tres grandes apartados glosan el eje temporal, mientras que el eje espacial atraviesa temáticamente toda la obra, ya que el autor pretende focalizar y extraer para su reflexión las características principales que para él definen la crisis de la modernidad.

El recorrido se inicia con «Dos estampas de la condición moderna», comprensivo de dos capítulos. En el primero «1789-1989: doscientos años de razón y revolución», se estudian las peripecias de la razón política ilustrada, desde la optimista declaración de intenciones hasta sus ominosas consecuencias no previstas, anticipadas por Tocqueville, radicalizadas por Weber y la teoría critica frankfurtiana, y continuadas por el criticismo contemporáneo. Lo más importante, a mi entender, de este recorrido bicentanario sobre estos dos tremendos descriptores «razón y revolución», reside en comprobar cómo el impacto de su contraste a lo largo del tiempo estimula en cada época su propia conciencia histórica, haciendo más reflexivo su nivel de perplejidad, mientras trata de emanciparla de la roma tendencia a la compulsividad.

Sin embargo, no participo de la conclusión de este capítulo en lo relativo a la antitragicidad de «la 
actitud liberal profunda», pues, en mi opinión, lejos de su abstracta luminosidad, las grandes obras del pensamiento científico social liberal (Simmel, Weber, Freud, Ortega) constituyen la desgarrada expresión del choque en la obra de la civilización, de sus causas telúricas y sus efectos indeseados. Arquitecturas trágicas en las que se revela que el mundo se mueve desde el abismo, llámese éste: tragedia de la cultura, petrificación mecanizada, desencantamiento, spaltung, hegemonía de la pulsión tanática sobre la erótica, historia bélica del mundo o vida como naufragio. Este liberalismo profundo paga con su trágica «conciencia desdichada» su distanciamiento de la hedónica y utilitarista retórica hacia el egoísmo individual y el bienestar masificado.

El segundo capítulo de este primer apartado es «La "historia del futuro" como diagnóstico al ternativo», en el que acudiendo al legado narrativo se presenta el aporte de la «ensayística de anticipación» llevada a cabo por H. G. Wells y W. W. Wagar. Dentro de la disputa epistémica Habermas $v s$ Rorty (iinventar mundos o resolver problemas?), Rodríguez Ibáñez bascula hacia las posiciones rortyanas, pues mientras Habermas pretende reconstruir el proyecto racionalista entendiendo el mundo como un "problema a resolver», el autor, junto con Rorty, prefiere acudir a otros lenguajes, como el narrativo, para ir encontrando descripciones y comprensiones que nos anticipen y esclarezcan las razones y sinrazones de nuestros sistemas de convivencia y de nuestras maneras de vivir. De ahí el acudir a la literatura de Wells y Wagar. Aunque indudablemente es arriesgada esta toma de postura a favor de la incorporación de la literatura para el análisis sociológico, no cabe duda de que a medida que va discurriendo el tiempo, y frente a las posiciones teórico-metódicas del «positivismo fuerte», esta incorporación de la narratividad nos facilita ir comprendiendo cómo toda lógica (de procedimiento) no es sino retórica; cómo todo sig nificado (de la explicación) no es sino contexto (de las condiciones de su producción); cómo toda máxima (metódico-técnica) no es sino particula ridad (de abordaje); y cómo toda conclusión no es sino interpretación.

El segundo apartado titulado «La herencia de los años ochenta» recoge tres estudios sobre los procesos sociales y políticos acontecidos en dicha década. Lo inaugura el estudio «El fin del valor central del trabajo», que versa sobre el desfondamiento del trabajo como utopía de cohesión social y anclaje personal y colectivo de los procesos identitarios. Le sigue el estudio sobre el "Poswel farismo" y "corporatismo": rasgos emergentes de la cultura política occidental»), para concluir con el estudio de las metamorfosis ideológicas de la izquierda desde el derrumbe del socialismo real ( "De la "nueva izquierda" a la izquierda indefini $d a »)$. Quizá se echan de menos como contrapunto, en el capítulo sobre «El fin del trabajo», las obras de autores más sensibles a los costes que dicho fin comporta. Pienso, por ejemplo, en La metamorfosis del trabajo de A. Gorz, El fin del trabajo de J. Riffin y Las metamorfosis de la cuestión social de R. Castel. Obras que, desde diferentes perspectivas, constatan dos cuestiones fundamentales: que la sustitución del trabajo, como matriz utópica de cohesión social, por la economía política, tecnológica y globalizadora, precariza tanto el trabajo (cada vez menos ligado a la continuidad), como los vínculos comunitarios, que son considerados cada vez más como un impedimento a la competencia económica. De ahí que el desanclaje espacio-temporal inherente a dicha tecnoglobalización desestructure el balance mínimo de cohesión social, el cual suele pendular entre el polo de la falta de suelo comunitario y sus peajes (anomía, inseguridad psicológica/ontológica, emergencia de la anarchical society de la que habla Hedley Bull), o su laterización hacia el exasperado retorno a las fuentes originarias (identidades etnonacionales y fundamentalismos).

Bajo el rótulo de «Un presente "postista"», el tercer gran apartado se adentra en el proceloso océano de las polémicas epistémicas más in fieri. Comienza con el capítulo "¿Posmodernidad, pos modernismo o hipermodernidad?: una toma de pos tura», en el que se realiza una revisión analítica de lo que subyace bajo el debate modernidad vs posmodernidad. José Enrique Rodríguez Ibáñez, alejándose del trazo grueso de la sociología mainstream (que aún suele etiquetar lo posmoderno como una unívoca opción caracterizada por el solipsismo fenomenológico, pleno de relativismo moral y sin validación metodológica alguna), aborda sin reparos el kairós de dicho debate, proporcionando un valioso mapa cognitivo imprescindible para definir la actualidad epistemológica de las ciencias sociales. Cabe matizar que la obra no pretende alcanzar la omniabarcante descripción del objeto de estudio, sino la aceptación consciente del proyecto hacia el que explícitamente se dirige la actual teoría sociológica. La escasez, sino carencia, de un itinerario contextuado de dicho debate en sociología, justifican en esta obra el abrir un observatorio para pensar tanto los límites de la modernidad (frente al finen sine fine de sus epígonos), como los espejismos y aporías de ciertas posiciones posmodernas.

Por otro lado y, dado el momento poliédrico de la sociología, tanto en sus contenidos como en la forma, Rodríguez Ibáñez opta, según mi juicio, por una anfibológica posición en la mentada polémica, pues quizá se ha perdido la posibilidad de realizarla 
de manera sencilla. Así, por un lado se posiciona a favor de las hipermodernas y constructivistas posturas de Habermas, Beck y, sobre todo, Luhmann, cuyo común denominador consiste en elaborar un marco conceptual que facilite el consenso en torno a las cuestiones heurísticas, teóricas y metodológicas. Mientras que, por otro lado, adopta posiciones más próximas al costado postmoderno, centradas en la adopción del «giro linguiístico» por parte de la teoría y la práctica sociológica, y cuyo botón de muestra es el capítulo sobre Wells y Wagar.

Continúa con «Senderos de posmodernización: ¿qué futuro nos aguarda?», una prognosis en torno a las tendencias sociológicas que pueden consolidarse en el primer tercio del siglo XXI. El libro se cierra con un apunte sobre «El proyecto europeo después de las grandes utopías», en su condición de recambio «minimalista» de las grandes utopías periclitadas. Respecto a este último capítulo $\mathrm{y}$, en aras a realizar algún apunte crítico que motive el ulterior debate, cabría argüir que frente al Ortega modernizador y europeísta de «La rebelión de las masas», que propone Rodríguez Ibáñez, existen otros «Ortega/s». Por ejemplo, el Ortega de la «España invertebrada», que plantea la mordiente cuestión sobre la identidad nacional, que delata, entonces y ahora, nuestra crónica falta de acoplamiento entre nación y Estado. Cabría incluso entender postmodernamente a Ortega, esto es, al Ortega más costumbrista de las páginas viajeras de «El espectador» o de sus célebres defensas de «La caza y los toros», como el comunitarista defensor de la cultura vernácula, frente a todo alambicado proceso de construcción (económica, política y administrativa) europeísta y/o globalizadora. Tres calas orteguianas a debate que constatan la extraordinaria vitalidad del pensador madrileño.

Escrita con fluidez y rigor, la obra que comentamos nos muestra que la actualidad de la producción sociológica está estrechamente relacionada con la crisis sociocultural en la que está inmersa, a la vez que patentiza la robusta musculatura intelectual de nuestro autor, que nos proporciona un punto de vista sustantivo sobre los acuciantes temas que se abordan. Una obra no cerrada, pero sí valiosa con la que tendremos que contar para seguir avanzando en el conocimiento de nuestras sociedades insertas en estos momentos de crisis de la modernidad.

Carlos Soldevilla Pérez 


\section{Globalización, riesgo, reflexividad. Tres temas de la teoría social contemporánea}

\section{Ramón Ramos y Fernando García Selgas (Editores) \\ CIS. Colección «Academia». Madrid. 1999}

Cuando uno últimamente se acerca a alguna de las pocas librerías que por estos pagos mantienen una $\mathrm{o}$, con suerte, dos baldas etiquetadas con el rubro «sociología», y lo hace, además, con la -inocente- intención de encontrar algo que se corresponda con eso que damos en llamar «teoría sociológica», la decepción y un cierto hastío (reediciones de o monografías sobre «los clásicos», manuales introductorios...) son sentimientos que aparecen con más frecuencia que la alegría o la sorpresa. Desde ese momento, caben apenas unas pocas posibilidades: dejar de leer, leer otra cosa, pasar a las secciones vecinas de «filosofía» o «antropología» con la esperanza de que los libreros se hayan confundido o refugiarse en las bibliotecas universitarias deseando que arriben tiempos mejores. No obstante, de vez en cuando suceden excepciones. Esta que protagoniza Globalizacíón, riesgo, refle xividad es una de ellas.

Una excepción, además, que ya ha emprendido el camino para dejar de serlo e institucionalizar su presencia en las librerías, pues este texto es parte de y contribuye a madurar una línea de debate, de reflexión y de creación teóricas que en el ámbito de la producción doctrinal de la sociología académica española viene apareciendo en la colección Acade - mia del Centro de Investigaciones Sociológicas desde hace ya algunos años: son ya, con éste, tres los volúmenes ${ }^{1}$, tres, también, los debates organizados y nueve los años de trabajo que esta compilación culmina. Topamos, pues, con una sociología madura, institucionalizada, alejada casi ya definitivamente del estadio divulgativo, sin, por eso, dejar de estar atenta a lo que se hace más allá de los límites de nuestras universidades. Sólo por eso la noticia de una nueva entrega de esta serie y la promesa de la llegada de algunas más merece ser celebrada con esperanza. Con suerte, no será necesario ni dejar de leer ni pasar a leer otras cosas.

$\mathrm{Y}$ es, a mi parecer, precisamente en esta condición institucionalizada de este texto y de lo que muestra que corre por detrás de su producción donde se encuadran no sólo los mayores méritos de este trabajo, sino también los que considero que son sus principales deméritos. Por entre los primeros despunta no sólo la abrumadora calidad y actualidad de las referencias (Barañano, García Blanco, Rodríguez, Rodríguez Ibáñez), los en general bien fundamentados cuestionamientos de clásicos y de no tanto (García Selgas, Sánchez de la Yncera), las vigorosas alternativas que se nos proponen (Beriain, de Marinis, Izquierdo, Navarro, Noya, Ramos), el ataque frontal a las lastrantes maneras de hacer de la teorización en sociología (Beltrán, Bilbao, Callejo, Murillo, Pérez-Agote), sino sobre todo el hecho de que, sin renunciar a su vocación de texto de referencia, este libro parece haber superado esa fase del ejercicio teórico en el que, según Merton, se repetía más veces de lo deseable la «atractiva pero fatal confusión de la teoría sociológica con la historia de las ideas». Por entre los deméritos, asoma un riesgo, acaso contrapartida inevitable de la institucionalización académica que pretende esta serie: textos desgajados de los temas que estructuran el volumen-deficiencia, es cierto, común a cualquier compilación que recoja los productos de un seminario o un congreso-; monólogos de algunos autores, empecinados en ocasiones en rebatir y/o confirmar lo sostenido en sus propias producciones anteriores dentro de esta misma serie; una cierta insistencia en el núcleo fundamental de autores que dan forma a los tres libros de la serie-que, regresaré sobre ello, en esta ocasión parece haber intentado romperse abriendo la puerta de entrada a algunas de las redes académicas ausentes hasta ésta de las otras entregas de la serie Academia-; y, quizás lo fundamental, una cierta pulsión a parir textos armados y cerrados, sobrecogedores por su limpieza de estilo, pero difíciles para poder jugar con ellos; difíciles, pues, para ser pensados y para pensar.

Pero los méritos y los deméritos de este volumen son distintos sólo en lo aparente, pues ambos son 
acompañantes forzosos del proyecto que se pretende instituir: conformar una serie de trabajos que muestren (en dos de sus sentidos: catas de «lo que hay» y textos de y para enseñar) el «estado de la cuestión» en la producción teórica de las universidades españolas. Por todo esto, este texto de refe rencia -debo resistirme a calificarlo de «manual», pues el sustantivo no haría justicia a lo más significativo del libro-, como la mayoría de los libros que comparten con él la misma vocación de mostrar y de enseñar, produce en el lector -al menos en éstetres efectos combinados: un incómodo sobrecogi miento, una cierta pereza, y bastante placer.

Por el primero paso de puntillas, pues es una manifestación normal de los «viajes» por textos actualizados y abiertos a los debates más calientes: asus$\tan$ y nos recuerdan que esto de la teoría no se aprende nunca del todo. En este sentido, que el libro se «conforme» con vérselas con riesgo, mundialización y reflexividad, «sólo» tres de los posibles palos a tocar dentro de la teoría social contemporánea, es un índice de modestia digno de ser mencionado y, sobre todo, agradecido.

En el segundo y tercero de los efectos del texto me detendré algo más. Decía Luis Martín Santos en su Diez lecciones de sociología, hablando de los libros que se escriben para enseñar esta materia, que «el espacio de la sociología no está encerrado en ningún discurso. La sociología no se puede aprender, hay que inventarla. Es algo que se busca, y ese algo sólo puede ser encontrado si somos capaces de inventarlo». De esa sociología que se escribe para ser aprendida viene la pereza; de la que se construye sabiéndose en invención procede el placer.

La primera, sociología a aprender, pasa por las contribuciones que se presentan más como un punto de llegada que como uno desde el que arrancar, más como reflejo de debates pasados que materia para trabajo futuro. Son estos textos diseñados para enseñar, entendiendo que esto es sobre todo un ejercicio de búsqueda y de revisión de fuentes y de orígenes, corriendo así los y las sabios que los escriben el riesgo -de él nos avisa Serres- de que, al encontrar las fuentes, en ellas sólo den con... otros sabios. Se mueven dentro de esta corriente, en mayor o menor medida, de un lado, los trabajos de A. Ariño, E. Gil Calvo y J. E. Rodríguez Ibáñez -ensayos muy documentados con los que se intenta, una vez más, salvar la fosa que separa la conceptualización de lo moderno de lo tradicional y de la modernidad de lo postsocial, con el mérito, en el caso del texto del primero, de introducir en esta serie referencias y estilos propios de los modos de hacer de la antropología-, de otro, M. Barañano -autora de un meditado, sistemático y prudente repaso de lo escrito por la sociología acerca del anclaje espacio-temporal de la socialidad humanay, por último, J. Rodríguez -que nos pone al día de lo trabajado por los sociólogos interesados en la temática del riesgo, aunque sin correr demasiados para hacerlo-. Deudores de este estilo son también, aunque en menor medida que los anteriores, partes importantes de los textos de F. García Selgas e I. Sánchez de la Yncera, las más propias de una suerte de «cirugía sociológica» que de los ejercicios de crítica, deconstrucción y creatividad teórica que los autores anuncian. Son todos, en suma, muestra de eso que A. Pérez-Agote (pp. 57-58) etiqueta como «teorizaciones frías», ejercicios producto de movimientos esencialmente intra-académicos, muestras de las piruetas que ha de inventar la sociología para su autoobservación y evolución. Son, no obstante, textos necesarios para dar consistencia al debate, lugares de paso que, aunque marcados por formas de hacer que recaen aún en un cierto regusto por el ajuste a la letra de obras pasadas y la exégesis, casi siempre fría y conclusiva, son sin duda imprescindibles: dan base a los pilares de la «ciencia normal» y marcan los límites de lo legítimo en sociología. Desbrozan, en suma, el terreno para otros ejercicios más arriesgados.

De éstos son buenas muestras los trabajos que provocan placer, sociologías en invención, textos que se hacen con pasión, se dice que así se hacen y, por eso, la provocan en el lector. Aunque en ocasiones inacabados, estos trabajos constituyen puntos de partida para prometedores diálogos futuros. Son trabajos deudores de la apuesta de Merton por las «teorías de rango medio»: ni simples muestras de empirismo abstracto, ni inescrutables tentativas ansiosas por reformular la Gran Teoría. Predominan en este libro. Y sólo eso es motivo de celebración.

Algunos de ellos, los que participan con más claridad de una lectura «moderna» del ejercicio teórico -la teoría como «red que se lanza para apresar el mundo», como la definió K. Popper- apuestan por cerrar más los nudos de esa red, sea desde el lado del objeto, revisando «enfoques teóricos que puedan resultar efectivos para confrontarse con formaciones empíricas» (p. 75), sea desde aquél que ocupa el sujeto, apostando por ajustar más la malla teórica que nos sirve para aprehender mejor lo que vemos. Del primero de los trabajos se ocupan, por ejemplo, A. Pérez-Agote -en una arriesgada muestra de las posibilidades del reciclaje teórico, aún inconclusa, pero con apuntes prometedores para los que trabajan empírica y teóricamente en el campo del estudio del mantenimiento, reproducción y la emergencia de las políticas en sociedades de estructura policéntrica-, o P. de Marinis -uno de los trabajos más impecables del libro y un muy útil instrumento para tematizar lo postsocial a través del 
cuestionamiento de dos de los soportes empíricos de la sociedad propia de la sociología moderna, el Estado y el ejercicio político-. Por cerrar la malla de la teoría desde la plataforma que ocupa el sujeto de la observación, apuestan los textos que fusionan paradigmas antes mutuamente excluyentes $o$ los que se abren a propuestas teóricas ajenas, en principio, al campo de la sociología. Es el caso, entre otros, de las contribuciones de J. Beriain -extraña y prometedora fusión de la (fría) sociología luhmanniana y de las (a veces tórridas) referencias a la sociología del imaginario-, García Blanco -en un intento, quizás algo denso, de fundamentar teóricamente la imagen del «sistema de la sociedad mundial»- o M. Beltrán -quien da un paso más en una línea de reflexión que abrió hace ya algún tiempo, definiendo el extraño territorio que han marcado como propio las ciencias sociales, el delimitado tanto por sus certezas objetivistas como por las dudas que proceden de la ya casi total autoconciencia del carácter construido y mediado de sus estrategias para saber-.

Otros, portavoces para la ocasión de una interpretación más encarnada del «hecho teórico» (la teoría entendida como participación en y del objeto), templan sus trabajos removiendo las piezas del núcleo problemático en el que quizás más se insiste a lo largo del libro: el de la interfaz que une y separa al sujeto de la observación con el sujeto que observa. Replantean, así, no sólo los contenidos de globalización, riesgo, reflexividad, temas de la teoría social contemporánea por los que se atreve a explorar este volumen, sino también el ejercicio teórico mismo que los constituye. Así, estos textos dicen no sólo del qué sino también del quién, del para qué y del desde dónde de esa enunciación y afrontan ese reto desde una u otra de estas tres estrategias: la tematización de la mutua constitución de ambos polos de esa extraña pareja, sujeto y objeto de la observación; la problematización, en cambio, de la flecha que va del sujeto hacia el objeto; o la pregunta, en fin, sobre qué ocurre con el objeto cuando es mirado por la sociología.

Engranan, en principio, con la primera estrategia los dos trabajos (J. Callejo y S. Murillo) que representan una de las apuestas arriesgadas de los compiladores, la de dar entrada en el «grupo de teoréticos» a investigadores que trabajan en el otro de los grandes compartimentos estancos de la sociología institucionalizada, el de la metodología, presente apenas tangencialmente en las anteriores entregas de esta serie. La tarea era sin duda difícil, y quizás por eso haya que esperar a próximas entregas para que se culmine, pues, así lo entiendo, en ésta no se ha logrado atacar con claridad el reto de disolver la pesada distinción entre teoría y práctica sociológicas. Acaso porque ambos trabajos siguen aún muy de cerca la estela de la obra de J. Ibáñez, cuestión que no es en absoluto negativa en sí misma, pero sobre la que cabría reflexionar en la medida que se repite con demasiada frecuencia. Y más aún si consideramos que el aliento fundamental de la obra de lbáñez empujaba a concebir la teorización como un trabajo de autoreflexión, de crítica y de cuestionamiento de los propios supuestos, acrobacias de gimnasia sociológica que, así lo creo, están aquí ausentes, encerradas en círculos hace unos años virtuosos por sugerentes y novedosos pero hoy ya viciosos por repetidos. Peligrosos además, pues conducen a que lo que fue heterodoxia devenga ortodoxia en los escritos y ortopraxia en la investigación social.

A través del cuestionamiento por el lugar de enunciación de la teoría se desplazan, por contenido, las contribuciones de F. García Selgas y P. Navarro y, por estilo, la de I. Sánchez de la Yncera. Entre las tres componen un bloque singular y alentador, articulando -sobre todo desde el trabajo del primero- una interesante novedad en las maneras de construir los debates teóricos que muestra este volumen, novedad que subsana en parte ese ligero deslabazamiento entre los distintos artículos que presenta esta compilación. Son artículos muestra de una apuesta, aún tenue, que se construyen con, contra y en paralelo al debate y el lugar que los posibilita y produce, haciendo del juego de ping-pong entre la deconstrucción y la reconstrucción teóricas estrategia de escritura y de estilo, lo que, no hay duda, facilita el pensar: el lector entra en el diálogo, el consumo del texto se hace productivo. Se puede, pues, inventar teoría. F. García Selgas lo hace desde un excelente reclamo para olvidar los supuestos unitarios que fundamentaban el campo de las ciencias sociales y una hábil denuncia de los recovecos por donde aún hoy se sigue colando esa arquitectura de lo social, con pertinentes anotaciones sobre un locus teórico sugerente y peligroso de la sociología actual, el de la identidad. Por su parte, P. Navarro, no sin riesgo, apuesta por la definición de una ontología de la socialidad humana muy abierta a nuevas incorporaciones conceptuales, aunque, a mi parecer, con un cierto peligro de inflación terminológica. Merece atención su noción de «dispositivo de interacción virtual», arma teórica potentísima para cerrar algunos viejos y pesados debates de las ciencias sociales, arma, que permite, además, vislumbrar una buena traducción a la sociología de los supuestos teóricos fuertes del constructivismo radical, casi siempre traídos por los pelos hasta nuestro terreno. Por último, I. Sánchez de la Yncera realiza una proposición de intenciones similares a las de Navarro aunque inspirada en fuentes más «sedentes», en la que sobresale la pasión del autor al darle forma y el 
reconocimiento implícito del carácter dialógico y compartido de la teorización en sociología. No pueden perderse, en ese sentido, las jugosas notas a pie que atraviesan todo el trabajo, repletas de diálogos, conversaciones, alumnos y colegas. Realización práctica del desvanecimiento, por reparto que no por muerte, del principio de autoría, tan moderno como el del supuesto-sujeto.

Por último, las aportaciones de R. Ramos, J. Noya y A. J. Izquierdo introducen un elemento inteligente y aún poco frecuente, el que procede de la interrogación por (i) cómo concebir un objeto que se sabe sociológicamente determinado y construido y (ii) cómo hacer investigación social y construir teoría sociológica ante un actor que considera esas coordenadas para su autoconstitución. El texto de A. J. Izquierdo, aunque lastrado por cierto encorsetamiento, derivado quizás de su condición de tesis doctoral, esconde supuestos teóricos de inmenso calibre en los que es uno de los pocos en atreverse a penetrar: la capacidad performativa del saber sociológico, su potencia para constituir paisajes habitables, territorios aptos para la socialidad. J. Noya, por su parte, da muestras no sólo de una desbordante capacidad de invención conceptual, sino también de una gran agudeza al trasladar al ámbito del consumo y de lo estético el lugar de constitución de la identidad del actor social, un lugar problemático para la sociología pues presupone un objeto competente para flexionarse sobre sí y un lugar de gestión de lo social que ya no puede concebirse sin considerar la incidencia sobre él de las distintas miradas (sociológica, económica...) que lo conforman. De nuevo en el terreno de la performatividad de la mirada sociológica, la contribución de R. Ramos imprime un giro perverso en la reflexión sobre la actividad teórica. Persistiendo con su profundización en la metáfora del homo tragicus y en la construcción de las consecuencias no intencionadas como lugar de observación, Ramos sondea aquí en la arqueología de la «parte maldita» de lo social para terminar proponiendo que ésta es, al menos en nuestros días, fuente y producto de su tematización sociológica. El «riesgo» es así no sólo un diagnóstico, sino también una «forma de nombrar, dar espacio y presencia al mal» que recrea lo que pretende exorcizar. Destino trágico el de la investigación social: todo lo que esclarece genera y es parte de un nuevo movimiento que da lugar a nuevas opacidades.
No tienen, pues, ni la investigación social ni la teoría sociológica, final posible. Tampoco en este libro. Tanto mejor; así se podrá seguir inventando teoría.

A textos como éste, concluyo, hay que plantearles dos series de cuestiones. De un lado preguntarles si enseñan, si son actuales, si alientan el debate y lo reflejan. A todas ellas la respuesta es, para el caso, positiva: este volumen muestra y enseña. Conforma, entonces, sociología a aprender y puede constituirse en texto de referencia y de trabajo académico. A esa tarea contribuiría mucho que, siendo como es un libro destinado a una consulta continua, y estando planteado como está para actuar a modo de «enseña» de la sociología que produce la Academia, se intentase, por parte de los responsables editoriales, recuperar la calidad de la edición de entregas anteriores de esta serie, así como evitar la presencia de algunos errores que una más cuidada corrección ortográfica habría podido subsanar. De otro lado hay que interrogar a estos trabajos por su capacidad creativa, demandarles, pues, nuevos conceptos, nuevas formas de hacer, nuevos cuestionamientos. También en ese segundo sentido la respuesta es positiva: aquí se inventa teoría. Cabe, no obstante, pedirle a quienes aseguran la continuidad de esta línea de trabajo que persistan, de un lado, en la intención que han mostrado en esta entrega de abrirse a otras redes de actividad académica, y de incrementar, de otro, la presencia de estilos y estrategias que ayuden a dialogar con el texto y desde los textos. Se evitaría, así lo entiendo, la pereza y se incrementaría la pasión y el placer en la lectura y en el debate.

Ambas se requieren para la institucionalización de la producción bibliográfica de la teoría sociológica. Si la cosa sigue por aquí, no parece que haya motivos para la desesperanza: podremos seguir leyendo sociología para hacer sociología.

\section{NOTA}

En 1992 vio la luz, editado por E. Lamo de Espinosa y J. E Rodríguez Ibáñez, Problemas de teoría social contemporánea, primer texto de esta serie, y en 1996, el segundo, Complejidad y teoría social, editado en esa ocasión por A. Pérez-Agote e I. Sánchez de la Yncera, ambos en la colección Academia del CIS.

Gabriel Gatti 


\section{Sociología del Conocimiento Científico}

\section{Juan Manuel Iranzo y Rubén Blanco}

CIS. 1999

En esta obra, los autores, especialistas en la materia y que han dedicado buena parte de su labor de investigación doctoral a ella, nos ofrecen un recorrido por lo que son los lugares, teóricos, históricos y programáticos, de la que actualmente se conoce como Sociología del Conocimiento Científico. Este campo de investigación sociológico se inauguró en los EE.UU. con la obra de Robert K. Merton, pero su evolución ulterior, proveniente del mundo anglosajón del otro lado del océano, marcaría lo que los autores denominan «revolución cognitiva» en el ámbito más amplio de la Sociología del Conocimiento. Veamos cómo ha sucedido esto.

En Teoría de la Ciencia, la visión heredada proviene del campo de la Filosofía Analítica: en esta disciplina se diseñaron los parámetros de lo que habría de ser la visión ortodoxa del conocimiento científico: como forma de conocimiento por excelencia, la ciencia debía ser concebida de modo que su fundamentación obedeciese a criterios de formalidad férreos y bien establecidos. Según la Filosofía Analítica, la ciencia se construye mediante procedimientos deductivos, encadenando proposiciones lógicas que se siguen unas a otras de forma necesaria y sobre las cuales se construye el armazón de la teoría científica, abstracta, impersonal, rigurosa y precisa. Sin embargo, esta visión de la ciencia, la visión «heredada» será la que un conjunto de autores en el campo de la sociología pondrían en cuestión a partir de los años setenta. El proyecto se originó en la Universidad de
Edimburgo, y sus fundadores lo denominaron el Programa Fuerte (PF) en Sociología del Conocimiento.

Dos precedentes ilustres abrieron el camino para esta renovación. Wittgenstein, con su filosofía del lenguaje, y Fleck, en el campo de la historia de la Ciencia, sentaron las bases que permitirían concebir la empresa científica como una labor humana, encarnada en sujetos inscritos en contextos sociales y dedicados a una actividad cuya formalidad aparente oculta todo un magma de procesos en los que se ven involucrados y que determinan la naturaleza de aquello a lo que están dedicados, la producción de conocimiento científico. No obstante, el detonante en este giro en la concepción de la ciencia fue, sin lugar a dudas, Thomas S. Kuhn, quien en su obra La estructura de las revoluciones científicas presentó una visión histórica de la ciencia que chocaba frontalmente con aquella que propugnaba la visión heredada. Kuhn articuló su concepción de la evolución del conocimiento científico a lo largo de la historia en torno al concepto de comunidad cien tífica, el conjunto humano aglutinado en la tarea de avanzar en un campo determinado de la ciencia, cada comunidad científica sería seguidora de un paradigma, un conjunto articulado de concepciones heurísticas, metodológicas y de procedimiento que guiaría la actividad cotidiana de la comunidad. Además, según Kuhn, la dinámica histórica de la ciencia no sería evolutiva, resultado de un progreso continuo y sin rupturas -algo que también propugnaba la visión heredada: el progreso científico sería acumulativo-, sino que lo que se dan son cambios revolucionarios de paradigmas, situaciones en las que las comunidades científicas entran en crisis porque el paradigma al que están adscritas no consigue dar solución a los problemas que van surgiendo, se generan lo que Kuhn denomina anomalías, que hacen entrar en crisis al paradigma y sólo son resueltas cuando un paradigma alternativo consigue la explicación deseada: la transición entre un paradigma y su sucesor no puede darse, según Kuhn, sin una revolución en el conocimiento de la comunidad que sufre esa transición.

La obra de Kuhn marcó el inicio de un debate acerca de la naturaleza efectiva del conocimiento científico, de su dinámica y evolución. Entre los autores implicados en este debate, cabría señalar a cuatro. En primer lugar, el «ácrata» Feyerabend, quien se mostraba partidario de una visión acerca de la ciencia que renegase radicalmente de la concepción que la filosofía de la ciencia tradicional venía propugnando. Según él, la operación principal mediante la cual el conocimiento científico evoluciona es la contrain ducción, un proceso mediante el cual, y pese a que según la evidencia inductiva el camino a seguir habría de ser distinto, los científicos, en innumerables 
ocasiones «apuestan» por la novedad, consiguiendo con ello avances significativos. Para Feyerabend, la ciencia es una actividad de carácter eminentemente local, que se desarrolla en el ámbito concreto en el que los científicos desempeñan su labor, de modo que la universalidad presupuesta de dicho conocimiento no es más que la reconstrucción racionalizada que sus defensores realizan ex-post-facto con el objeto de legitimar los productos resultantes de dicho conocimiento. En línea enfrentada con él, estaría Lakatos, quien propugnaría la denominada Metodología de los Programas de Investigación Científica. El intento es, en resumidas cuentas, el de una reconstrucción normativa de la evolución científica que, en la línea de la tradición heredada, pretende legitimar la excelencia de la ciencia como forma de conocimiento. Según Lakatos, es posible generar una visión retrospectiva de la ciencia que estructura de forma absolutamente racional la evolución que ésta ha sufrido a lo largo de la historia y da cuenta de los cambios que ha conocido en consonancia con los requisitos lógico-formales que exigía la Filosofía Analítica. Toulmin, por su parte, era partidario de una visión que concebía a la ciencia como un proyecto de adaptación progresiva al entorno inmediato y concreto al que se tenía que enfrentar. Si bien se trata de una visión evolutiva, la excelencia de la ciencia no vendría garantizada, como quería Lakatos, por su racionalidad intrínseca, sino por el hecho de que sería la mejor forma de resolver los problemas específicos y concretos con los que se topaba, independientemente del modo en que esa solución fuese conseguida. Por último, cabe señalar la aportación de Mary Hesse, la cual, desde una perspectiva antropológica, defendió que la ciencia operaba eminentemente mediante analogías, no por deducción y por consecución de proposiciones lógicamente estructuradas; existiría lo que ella denomina un sistema primario y un sistema secundario: el sistema primario sería un conjunto entramado conceptual eminentemente descriptivo, resultado de la observación de y el contacto directo con la naturaleza, mientras que el sistema secundario establecería relaciones analógicas y abstractas entre los elementos del sistema primario, de modo que conjugándolos obtendría explicaciones plausibles y operativas de aquello que el sistema primario simplemente describiría.

Ahora bien, este debate, así como los autores involucrados en él, no se desarrollaba dentro del campo de la sociología. En éste, los precedentes propiamente dichos hay que situarlos, por un lado, en Maunheim, con su sociología de la ideología, quien en el afán de determinar las bases existenciales del conocimiento, definió una «zona de exclusión»en la cual el conocimiento científico quedaba al margen del análisis sociológico debido a que su natura- leza sería tal que no incidirían en su elaboración factores de tipo social. Y por otro lado estaría el ya mencionado Robert K. Merton, quien sí aceptaría a la ciencia como objeto de estudio sociológico, pero delimitando muy precisamente el ámbito de competencia de la sociología de modo que no se inmiscuyera en cuestiones de índole epistemológica.

Según Merton, la ciencia sería una máquina de comunicación perfecta regida por unos imperativos morales, un ethos científico, entre los cuales los principales serían: el Comunalismo -la ciencia opera de manera colectiva y cooperativa-, el Universalismo -el conocimiento científico es de carácter universal e independiente de las circunstancias particulares en las que pueda ser puesto en juego-, el Desinterés - los científicos realizan su labor de manera altruista sin buscar en ella beneficios personales-, y el Escep ticismo Organizado-los científicos, por principio, recelan de cualquier novedad y la someten sistemáticamente a pruebas antes de aceptar su validez- . Según Merton, la base existencial de la estructura organizacional de la institución científica sería la garante de su excelencia como conocimiento.

A esta visión normativa, institucional y funcionalista se le opusieron una serie de críticas. La principal de ellas provino de Mulkay; según este autor, la conducta real de los científicos no se rige por normas, dado que una misma acción puede ser producto de varias normas distintas, en tanto que, además, un resultado satisfactorio puede haber sido el producto de lo opuesto a lo que una norma prescribiría. La ciencia, afirma Mulkay, se constituye en base a un aprendizaje en el cual se inculcan saberes pragmáticos y tácitos -no regulables normativamente-, junto con los dogmas de la profesión -que sí serían valores de orden normativo, pero cuya función no sería tanto la regulación de la conducta de los miembros cuanto la de legitimar su estatus y excelencia-. Por su parte, la respuesta de Ziman a la visión mertoniana fue la defensa de la idea de que la ciencia opera como un mecanismo de intersubjetividad consensuada y que su producto, la verdad, no es más que ese consenso establecido entre los miembros de la comunidad-, la ciencia sería, así, el resultado de una práctica social e históricamente situada- «La ciencia es indeterminada y falible porque sus reglas de validez y las normas que rigen su producción y distribución no transcienden sus circunstancias históricas y su medio social» (p. 134).

En la línea de estas críticas al programa mertoniano, pronto muchos autores estuvieron de acuerdo en el hecho de que la regulación normativa de la conducta y la prescripción de la acción mediante reglas técnicas es algo que cambia en el tiempo, y que ese cambio tiene lugar por y desde contextos sociales, afectando a la propia substancia del conocimiento 
producido por los sujetos implicados en la actividad científica. De este modo, sociología y epistemología, lejos de ser interpretaciones distintas del hecho científico, tenderían más bien, a asimilarse. La tarea sería, entonces: «Discutir, no lo que debe contar como conocimiento científico, sino lo que realmente se tiende a tomar como tal» [Dolby] (p. 138).

La evidencia, destacada por la Antropología, de la diversidad cultural, generó un debate en torno al criterio de evaluación que se debería aplicar para la comparación de las distintas culturas, puesto que si bien en un principio el rasero que se aplicó fue el de la racionalidad occidental, bien pronto se pudo comprobar que se trataba más bien de un sesgo etnocéntrico de los analistas dedicados hasta entonces al estudio de las tribus exóticas. Winch señaló, en oposición a esta tendencia etnocéntrica, que el conocimiento de otra cultura no se alcanza traduciéndola a la cultura propia, sino, muy al contrario, alcanzando competencia como nativo de dicha cultura. Concluía, de ello, que no era posible la comparación de culturas distintas -entre culturas distintas se produciría una situación de inconmensurabilidad-. Pero, en oposición a esta tesis, el intento en el campo antropológico era la búsqueda de una heurística que permitiese la comprensión universal de culturas y creencias diversas; es decir: la búsqueda de un patrón común de interpretabilidad de la diversidad.

Este debate, suscitado a raíz de la diversidad cultural, giró en torno a cuatro cuestiones centrales. En primer lugar, se trataba de decidir si la racionalidad era un hecho universal -se trataría, entonces, de la racionalidad occidental, y en ella estaría ese deseado patrón común de interpretabilidad- o bien si lo que había que considerar era la existencia de múltiples racionalidades distintas. En segundo lugar, estaba la cuestión del relativismo, es decir, la cuestión de si existían «universales cognitivos», esto es, si la diversidad cultural debía ser entendida como un hecho natural -y entonces no existirían tales universales-, o bien, al contrario, como el resultado de la desviación de un «standard óptimo» -y, nuevamente, la racionalidad occidental sería dicho standard-. En tercer lugar, estaba la cuestión de la traducción: ¿era posible trasvasar los elementos de distintas culturas entre sí, de modo que pudiese darse una inteligibilidad compartida, o bien dicho trasvase no era posible y habría, como reclamaba Winch, que apelar más bien a la competencia como nativo? Por último, y en relación con el aspecto anterior, estaba la cuestión de la inconmensurabilidad: el problema de aceptar que entre distintas culturas no existía la posibilidad de establecer puentes de comunicación y entendimiento, o bien rechazar esta posibilidad.

Sería este debate, unido a los problemas que habían suscitado tanto la interpretación mertoniana como las corrientes tradicionales en filosofía e historia de la ciencia, el que posibilitaría el giro que se iba a operar en el campo de la sociología en lo que se refiere a la interpretación del «objeto ciencia». En 1964 se funda la Science Studies Unit en la facultad de ciencias de la Universidad de Edimburgo. En ella, Barry Barnes y David Bloor constituirán el PF: tomando elementos diversos de la filosofía de Wittgenstein, de la sociología de Mannheim y Durkheim, de la antropología de Douglas, propugnan el estudio sustantivo del conocimiento científico desde una perspectiva sociológica. Afirmarán que la ciencia es una práctica local, convencional y contingente, históricamente situada y socialmente configurada, practicada por actores guiados por intereses particulares. La producción de conocimiento está sujeta a negociación y el sentido de lo que se dice y lo que se hace surge de la práctica cotidiana y no de patrones abstractos normativos que dicten el modo de actuar.

Señalemos cuáles son los principales rasgos teóricos del PF:

En primer lugar, el Naturalismo y el Realismo. La interpretación debe anclarse en aspectos materiales y fenoménicos, no en entelequias e idealizaciones; a la vez, ha de aceptarse la existencia de un mundo externo, independiente y único. Ahora bien, la relación cognitiva establecida con ese mundo da pie a múltiples concepciones alternativas: el substrato material no determina el conocimiento adquirible sobre él. Estas distintas concepciones posibles dependen fundamentalmente de las condiciones sociales en las que se gestan. Por lo tanto, el conocimiento es, constitutivamente, social.

En segundo lugar, el Inductivismo y el Finitismo. El conocimiento científico opera exactamente igual que el conocimiento común, esto es, por analogía e inducción. Son los usos lingüísticos sucesivos los que generan el significado de los conceptos: las teorías no abarcan nunca todos los casos posibles, de modo que la deducción no es una fuente definitiva de conocimiento. El mecanismo básico mediante el cual se adquiere conocimiento es la ostensión -la aplicación sucesiva de conceptos a distintos casos particulares, concretos, con los que el hablante se va topando-, practicada en contextos concretos de aprendizaje. La formalidad del conocimiento científico no es un rasgo de su proceso de producción sino una reinterpretación que del mismo hace la ortodoxia que lo practica. Además, el conocimiento científico, lejos de ser entendido como el resultado de la práctica de una actividad dotada de una excelencia epistémica particular, ha de ser visto, más bien, como un intento práctico e inmediato de adaptación a las circunstancias que la vida hace enfrentar a los sujetos. 
En tercer lugar, el Relativismo y la Racionalidad Natural. No existen criterios «naturales» en función de los cuales poder jerarquizar la excelencia racional de producciones culturales distintas. Sin embargo, cabe señalar que para el PF existen la verdad y la naturaleza, pero defiende que no es posible mediante ellas establecer una delimitación entre lo que sería conocimiento propiamente dicho y lo que simplemente sería opinión. La contextualidad histórica que caracteriza a los procesos de producción de conocimiento, y a los sujetos en ellos involucrados, hace que verdad y naturaleza $-\mathrm{O}$, al menos, las representaciones utilizadas para referirse a ellas- sean constructos sociales. La racionalidad natural de la ciencia es exactamente igual, la misma, que se aplica en el razonamiento común, es decir, la especificidad de la ciencia como actividad productora de conocimiento no se basa en un tipo de racionalidad sustantivamente distinta de aquella que aplican los sujetos en contextos no dedicados a la producción de conocimiento científico, dicha especificidad ha de ser situada en los procesos sociales mediante los cuales los científicos ponen en juego una racionalidad que es la misma que se aplica en el razonamiento común.

Y, en cuarto y último lugar, el Instrumentalismo Sociológico y la Explicatividad. El PF persigue como fin la construcción de argumentos que expliquen cómo se produce el conocimiento. La inscripción de todo conocimiento en una cultura es lo que determina que dicho conocimiento sea instrumental: se genera para el cumplimiento de unos fines o intereses, del tipo que éstos sean, inscritos en los principios rectores de la cultura de acogida. Es decir, es la cultura, por ende, la sociedad, la que determina la orientación, el valor y el sentido de la actividad destinada a la producción de conocimiento: explicar cómo eso sucede es el objetivo perseguido por el PF.

Sobre la base de estos presupuestos teóricos, el $\mathrm{PF}$ definió sus cuatro principios programáticos. El principio de causalidad, que establece que las explicaciones que han de darse a estos procesos de producción tienen que ser de tipo causal -aunque bien entendido que no ha de concebirse la causalidad sensu stricto, al modo determinista o probabilista propio de las ciencias naturales, sino más bien en el sentido interpretativo y hermenéutico característico de las ciencias sociales (algo explica algo $\mathrm{y}$, entonces es causa de ello, si le confiere sentido e inteligibilidad)-. El principio de imparcialidad, que establece que las razones que aduzca el investigador no pueden obviar las razones de los sujetos investigados; no hay que prejuzgar la definición de la situación que sus actores promulgan sino tenerla en cuenta como un elemento, y un elemento relevante, de la propia situación. El principio de si metría, en virtud del cual se postula que el mismo tipo de explicaciones que se den para los casos de conocimiento finalmente sancionado como exitoso o «bueno», han de ser aducidas para aquellos otros en los que de lo que se trate sea de intentos «fallidos», esto es, de procesos cuyo resultado, a posteriori, fue juzgado cómo erróneo o «malo». Por último, el principio de reflexividad, según el que, dado que la pretensión del PF es una explicación cientí fica de los procesos de producción de conocimiento científico, las mismas explicaciones que desde él se produzcan, deben de poder ser igualmente aplicadas sobre sus propios productos y afirmaciones.

Estos cuatro principios programáticos se estructuran en dependencia de una Teoría de los Intereses, que es la que le confiere al PF su naturaleza sociológica: «La teoría de los intereses... que es el núcleo duro de las explicaciones del PF, intenta superar los dos principales obstáculos que dificultan la comprensión de la interacción social: la indefinida complejidad descriptiva de la situación y la inaccesibilidad del significado subjetivo que le confieren los agentes» (p. 251).

En conjunto, anclado en las directrices de todos estos principios rectores, la «revolución cognitiva» del PI consistió, básicamente, en la desmitificación de la cosa ciencia. Por un lado, su excelencia dejaba de ser considerada una marca constitutiva de ella misma en cuanto tal, para ser redefinida como el producto de las negociaciones, la contingencia, la contextualidad, el localismo, etc. de la práctica que le da origen. Por otro lado, la sociología, digámoslo así, «entraba a saco» en el estudio del objeto científico, se liberaba de esa zona de exclusión que le impedía considerar como objeto propio la substancia, el contenido mismo de la ciencia: la ciencia podía ser considerada por la sociología, no como una institución en la cual podía determinar su estructura, sus organigramas, sus relaciones de poder o su sistema de valores y roles, dejando de lado los contenidos de lo que dicha institución producía, la ciencia podía ser estudiada sociológicamente en cuanto conocimiento propiamente dicho, y ello, precisamente, porque ya no cabía considerarla como El Conocimiento, con mayúsculas, sino como un tipo particular de conocimiento, en paridad con otros posibles.

Por supuesto, la respuesta a este programa de investigación no se hizo esperar, y provino de diversos frentes. Los mertonianos, los filósofos de la ciencia y los racionalistas orientaron su ataque contra la perspectiva relativista del PF; todos ellos pretendían salvaguardar el criterio de excelencia epistemológica de la empresa científica, aunque cada cual por motivos diversos. Los naturalistas, desde una perspectiva que los autores definen como «ingenua», se enfrentaban al pragmatismo y escepticismo del tipo de naturalismo que propugnaba el $\mathrm{PF}$, dado que, en 
definitiva, la naturaleza no era la determinante última del conocimiento, si bien su existencia no era cuestionada, esa negación del determinismo no era aceptable por la corriente naturalista ortodoxa. Sin embargo, pese a las críticas que suscitó, o más bien cabría decir, gracias al refuerzo que la respuesta a dichas críticas le proveyó, el PF consiguió una cierta consolidación. Si bien, ni mucho menos, consiguió alcanzar la posición de versión ortodoxa, su aval venía dado por los numerosos estudios de caso que su programa dio a luz.

Estos estudios de caso se orientaban en torno a dos temas nodulares: la producción social de conocimiento científico, por un lado, los usos sociales de las ciencias naturales, por otro. Los trabajos de Bloor acerca de las matemáticas, las compilaciones Natural Order y On The Margins of Science. Scien ce in Context, o el trabajo de Shapin y Shaffer Leviathan and de Air-pump: Hobbes, Boyle and The Experimental Life (que son sintetizados por los autores en el capítulo 10), eran trabajos que ponían en evidencia la productividad del programa en el estudio de casos concretos, en los cuales la visión que el PF propugnaba acerca de la ciencia se veía ratificada.

No obstante, había un déficit que el PF propiamente dicho no fue capaz de subsanar: su perspectiva teórica y su orientación metodológica demandaba imperiosamente la prosecución de trabajos empíricos que observasen sobre el terreno cómo, efectivamente, sus principios explicativos tenían una sólida base argumental. Fueron otros autores los que emprendieron este camino.

Sin duda, el trabajo al que se le atribuyó la inauguración de esta línea de investigación empírica fue Laboratoy Life, la obra de Bruno Latour y Steve Woolgar. En ella, se dedican a la investigación de un laboratorio de bioquímica y estudian cómo se dio el descubrimiento de una substancia, el TRF, interpretando todo el proceso de trabajo en el laboratorio como un proceso de generación de inscripciones. En esta obra, la perspectiva metodológica, el trabajo de campo antropológico cobra una importancia crucial, pues los autores han de decidir a priori cuál va a ser su postura cómo analistas frente a la «tribu» que será su objeto de estudio, optando entonces por una perspectiva ethic en la cual los argumentos y justificaciones de los científicos habrán de ser pasados por el tamiz de un cierto escepticismo sociológico.

Otro monográfico de corte antropológico fue la obra The Manufacture of Knowledge, de Karin Knorr-Cetina. La actividad del laboratorio, en esta obra, es descrita como un proceso de negociación en el que se establecen selecciones guiadas por intereses; además, el artículo científico formal, concebido como fuente fundamental de orden, es considerado desde la perspectiva de una doble función: estabiliza las inscripciones generadas en el laboratorio redefiniéndolas como hechos, pero también descontextualiza la producción misma de conocimiento otorgándole la apariencia de un fenómeno estrictamente formal y abstracto,

Junto a estas dos obras en concreto, se generaron algunas corrientes cuya pretensión era, precisamente, la construcción de argumentos a partir de estudios empíricos específicos. Entre ellas cabe destacar tres: El Programa Empírico del Relativismo (EPOR), la Sociología de la Traducción, y la Teoría del ActorRed. Por otro lado, también se iniciaron estudios en el ámbito de la sociología de la tecnología que trataron de aplicar los presupuestos de la sociología del conocimiento científico a este campo mediante, también, estudios concretos de caso.

El EPOR, instaurado por Collins y Pinch, plantea orientar la investigación hacia el estudio de las controversias científicas, pues en ellas el analista no necesita relativizar el conocimiento puesto en juego dado que son los propios agentes implicados en la controversia los que lo hacen, en su intento por deslegitimar la postura de sus rivales. Collins y Pinch realizaron varios estudios de caso analizando el hecho de la replicación experimental, para comprobar cómo los procesos de negociación, de sanción informal de conductas y la interacción social determinaban el sentido, la aceptación o rechazo como válida, de una replicación. Por su parte, la Sociología de la Traducción, de Bruno Latour, y la teoría del Actor-Red, de Callon, pueden ser consideradas dos versiones de un mismo planteamiento teórico: la concepción de la ciencia como una actividad en la cual se encuentran implicados elementos de naturaleza muy heterogénea -personas, instrumentos, política, economía, relaciones de poder, localizaciones geográficas...- cuyo entramado de relaciones genera un flujo constante de información entre todos los puntos de esa compleja red, flujo mediante el cual se determina lo que vale y lo que no vale como ciencia, quienes ganan y quienes pierden, qué alianzas se establecen para obtener la victoria frente a los contrincantes,... en definitiva, cómo la conjunción de todos los factores intervinientes, materiales y simbólicos, detremina el sentido, maleable, cambiante y continuamente negociado de la empresa científica. Estas dos corrientes teóricas inauguran la postmodernidad en el campo de la Sociología de la Ciencia.

Hasta aquí hemos considerado el contenido de la obra, nos resta ahora considerar el significado, teórico y programático de la misma. Sociología del conocimiento científico es un buen punto de acceso a dicho campo de la Sociología, y su virtud principal es la de facilitar abundante información, en 
forma de nombres y bibliografía, que permitirá al lector interesado profundizar en aquellos temas que más sean de su interés. Se nos explica con claridad y detalle cuál ha sido el giro que se ha dado desde los primeros estudios en el ámbito de la Sociología de la Ciencia, inaugurados por Merton, hasta las nuevas interpretaciones como la latouriana.

Sin embargo, el mismo déficit que los autores señalan que ha padecido el PF en lo tocante a las investigaciones empíricas se reproduce en esta obra. Obra que, básicamente, es una lectura, inteligente y provechosa, de lo que otros autores han venido diciendo. No existe una aportación sustantiva, basada en algún estudio de caso empírico concreto, mediante el cual se nos muestre cómo esos principios teóricos pueden ser puestos en juego. Y es esta una laguna que todavía ha de ser recubierta en nuestro país, puesto que desconozco la existencia de trabajo alguno en el campo de la SCC que haya sido emprendido sobre el terreno. Desde la experiencia de quien esto escribe, un trabajo de este tipo arrojaría luz sobre las fallas de que adolecieron los estudios fundadores de esta corriente empírica en la SCC, como es el caso de Laboratory Life. $Y$ es que todavía se sigue padeciendo en el estudio sociológico de la ciencia un síndrome de inferioridad, achacable, a mi entender, al hecho de que la preeminencia de la ciencia como fuente de conocimiento, como saber por excelencia, sigue siendo una traba incluso para autores que afrontan un programa crítico con esta visión. Es el caso que ha habido muchos científicos que han dado el salto desde sus especialidades al campo de la reflexión sociológica para explicar aspectos de aquello que fue su tarea profesional, pero no ha habido, que yo sepa, ningún sociólogo que haya dado el salto inverso, con la pretensión, a mi modo de ver, fundamental, de establecer una situación de igualdad mediante la cual poder afrontar un diálogo fructífero con los científicos, su labor y sus productos. Mientras no se de ese salto, la SCC será prisionera de sus propias afirmaciones, dado que su pretensión de cientificidad siempre será cuestionada por aquellos, los científicos que son su objeto de estudio, que dicen estar en posesión del único y exclusivo modo posible de hacer ciencia. Pese a ello, el paso que supuso la creación del PF, y los estudios posteriores que siguieron sus directrices, no puede sino ser considerado, efectivamente, como los autores lo denominan, una «revolución cognitiva»; lo que ahora hace falta es asentar las nuevas bases de la empresa científica construibles a partir de esa revolución.

En otro orden de cosas, se aprecia al leer este libro, un problema que parece hasta el momento no haber solucionado la SCC: el problema de encuadrar el conjunto de sus afirmaciones y argumentos en un marco teórico propiamente sociológico. Nos referimos a la problemática Teoría de Intereses sobre la cual se pretenden anclar los principios programáticos del PF. He de asumir que los autores son conscientes de esta falla, si bien tratan de eludir su consideración: ¿Qué sentido tiene cuestionar las interpretaciones formalistas tradicionales de la ciencia, apelando a la necesidad de un tratamiento sustantivo del objeto científico, si la operación subsiguiente a la constitución de un conjunto de presupuestos teóricos «revolucionarios» es la de retrotraerlos hacia una querencia de la tradición, esta vez, sociológica, igual de formalista que las interpretaciones criticadas? Si la concepción de la actividad científica como un proceso deductivo de encadenamiento lógico de proposiciones es formalista y justificativa, exactamente igual sucede al apelar a la interpretación de la actividad científica como el resultado de unos procesos cuya razón última estaría en los -obscuros e inalcanzables, subjetivos e individuales- intereses de los actores implicados. Se trata, nuevamente, de un formalismo legitimatorio que pretende dar carta de validez a las interpretaciones sociológicas porque se anclan en un postulado que históricamente ha pertenecido a la Sociología. Considerar que el motor de las negociaciones locales y contingentes en las que se embarcan los científicos al hacer ciencia son sus intereses nos devuelve a interpretaciones del tipo de las que propugnaba el individualismo metodológico: sólo es rastreable la conducta de los individuos, la evidencia de su acción, aunque no el sentido que para ellos tiene, sentido que, en último término, es irrelevante, puesto que el analista puede construir una interpretación externa de dicha conducta cerrando la problemática de su motivación bajo la etiqueta de «interés», que, en sí mismo, puede ser dejado de lado.

Por último, y en estrecha relación con lo anterior, hemos de señalar que no se presta la atención necesaria a la cuestión de la reflexividad. Los autores no hacen notar el corte epistemológico que suponen las interpretaciones de Latour y Callon, las teorías de la traducción y del actor-red, respecto a las propuestas originales del PF. Porque dichas formulaciones, lejos de constituirse en continuidad con los presupuestos fundadores de la SCC a modo de complemento empírico, apuntan hacia la solución del problema señalado en el párrafo anterior. Desde una postura realmente reflexiva, la apelación a una Teoría de los Intereses que ancla la explicación de los procesos sociales de la producción de conocimiento científico en la subjetividad de los actores no es sostenible, puesto que, como actores, y dado que, hemos de asumir, ellos sí son dueños de su propia subjetividad, los autores de la SCC habrían de explicitar los intereses que orientan su actividad, pues en su 
caso, dichos intereses no se escapan a la interpretación. Por eso, la concepción de la dinámica de la producción y distribución de conocimiento científico, como el entramado de relaciones que se dan entre elementos humanos, materiales, simbólicos e informacionales, sin distinción de precedencia entre los mismos, permite una concepción sociológica -dado que todos esos elementos se constituyen y adquieren sentido en contextos socales- son fruto, a su vez y en el mismo sentido, de relaciones sociales preexistentes- que no ha de apelar a mecanismos explicativos que se legitimen por la tradición de la disciplina. No es retórico afirmar que no se puede afrontar un estudio científico de la ciencia no reflexivo. Tomar críticamente la ciencia como objeto de estudio, obliga a volver la mirada sobre uno mismo y aceptar que todo aquello que afirme de su objeto de estudio lo está afirmando simultáneamente de sí mismo, lo cual, naturalmente, ha de incidir de alguna manera en eso mismo que pretende decir. En relación con esto es que, como ya he dicho, considero fundamental la investigación empírica de los procesos de construcción de las herramientas que conceptual y operativamente les permiten a los científicos ser tales y actuar como tales: no se puede estudiar la ciencia desconociendo el lenguaje que le sirve de soporte si es que se quiere acceder, realmente, a los contenidos del conocimiento científico para evidenciar su naturaleza constitutivamente social.

Miguel A. V. Ferreira 


\section{Los guardianes de la tradición Ensayos sobre la «invención» de la cultura popular}

\author{
Luis Díaz G. Viana \\ Sendoa Editorial. Colección de Antropología y \\ Literatura Oiartzun, Gipuzkoa, 1999
}

\begin{abstract}
«No se descubre al pueblo, se le crea, se le inventa. Pero alguien debe tener la autoridad suficiente de certificar la autenticidad de lo popular, aún en sus imitaciones. Y sólo podrán hacerlo aquellas grandes almas de la humanidad a quienes Hugo había comparado con «grandes árboles en el bosque», los guías, los iluminados, los hombres con una importante misión.»
\end{abstract}

Inspirados por la urgencia histórica de repensar el destino en construcción, los disidentes del racionalismo ilustrado y sus proyectos se lanzaron a la búsqueda de alternativas en las fuentes que la Ilustración había desautorizado. Pero el domino del espíritu iluminista era profundo, es profundo, y las alternativas oscuras. Pronto, esta disidencia se quedó enredada en las paradojas de la realidad que producía y buscaba al mismo tiempo.

Luís Díaz G. Viana dilucida las peripecias de este enredo. Tres ensayos van alumbrando los senderos que recorren «los guías» de esta búsqueda disidente. Y, si bien son variados, abundantes en contradicciones, divergentes en inspiración y logros, todos convergen en un cruce de caminos que les da sentido de conjunto como esfuerzo unívoco: la forja de la «cultura popular»... en aras de su «descubrimiento».

Las reflexiones del autor están cruzadas por la lógica de las dicotomías clásicas alrededor de las cuales se ha construido el debate sobre la cultura, en especial sobre la propia: rural-urbano, tradición- progreso, local-universal, popular-culto... Y el trasfondo que hace pertinente la discusión en estos términos es la concepción de la cultura y su devenir histórico como diálogo entre la Gran Tradición y la Pequeña Tradición. La «invención de la cultura popular» es también la génesis de esta concepción de la cultura.

Durante el siglo XVIII se había venido consolidando un modelo de cultura coherente con el clasicismo y el absolutismo. El modelo de cultura que sería identificada más tarde como la Gran Tradición. El paradigma ponía énfasis en el progreso humano y racional, cuyos gestores serían las elites cultas, urbanas y tempranamente cosmopolitas. Este ideario tuvo como respuesta y consecuencia la revisión romántica de las tradiciones, a la búsqueda de un sujeto «popular» depositario de una verdad local pero «auténtica», custodio de las esencias nacionales que deberían alimentar el destino histórico de los nuevos estados. $\mathrm{Y}$ tan pronto los románticos intentaron descubrir estas esencias, advirtieron al unísono la inminente amenaza que El Progreso cernía sobre ellas. Luís Díaz G. Viana reconoce en esta actitud una «impresión de época» (p. 73). En efecto, este vértigo romántico ante la pérdida del pasado y la identidad, viene a ser la contraparte de la apoteosis progresista de la Ilustración, ambas en el horizonte de una modernidad caracterizada, como afirma Heiddeger, por la conciencia epocal.

Llamando la atención sobre lo popular, contra 1o culto», los románticos habían pretendido, en primer lugar, honrar los saberes locales. Reivindicaban el ser rural que los conserva, dignificando el universo en decadencia de las provincias. Con ello se abre el camino a una nueva sensibilidad de la que habrán de alimentarse folkloristas de varias clases, tradicionalistas, «etnógrafos de lo propio», antropólogos, etc. «Especialistas» que durante mucho tiempo estarían en abierta confrontación por la conquista de su espacio de acción y de reconocimiento. La nueva sensibilidad que les movía es situada por el autor en el contexto de una sociedad cambiante. Díaz atribuye la invención y consolidación de la utopía rural a la nostalgia de los desplazados por el nuevo orden, vislumbrando el precedente del paradigma urbano asociado a la anomia. Así, los emigrantes campesinos que engrosaban la baja burguesía, los «modestos empleados»o los «atemorizados menestrales supervivientes de las revoluciones perdidas» se aliaron con las viejas elites rurales (desorientadas en la ciudad y despojadas de los privilegios sociales vigentes en el campo), para forjar un ideal. Era el relato de un «pueblo» mítico, en cuya definición tuvo mucho que ver la experiencia cercana de las masas urbanas, el temor y el desprecio al griterío de la turba descontrolada. Y con esta referencia urbana 
se iba reconstruyendo el campesino de vida armoniosa, que antes, como después y en muchas otras ocasiones, había sido sólo ignorante y atrasado.

Los «tradicionalistas» se apoyaron en los presupuestos del evolucionismo cultural para considerar las costumbres «del pueblo» vestigios de una pasado ancestral a la vez que apelaban al «genio colectivo» manifiesto en tales costumbres como fundamento del nuevo sujeto en construcción, la Nación. Pasado y futuro se implican en el continuo de la identidad nacional. Luís Díaz G. Viana nos llama la atención sobre la trascendencia política de este pensamiento. Lo que estaba en juego, no es sólo conservación de las costumbres y la nostalgia de la armonía rural, sino la pureza del origen, la «autenticidad» singular de lo propio, la certeza de la identidad contra el incierto proyecto de lo universal. Y en esta apuesta, la conservación de las sustancias nacionales y todo este beatífico orden del campo estaban acechados por los rápidos cambios sociales, políticos, etc., del momento. La consigna fue el rescate.

El espíritu de urgencia con el que los investigadores de diversos campos se lanzaron al encuentro de las tradiciones y su sujeto «popular» es fundamental para entender la gestación de la «cultura popular» en la dimensión arqueológica que se le ha dado. El autor hace una caracterización ejemplar de los folkloristas en este sentido. Muy en especial de la figura del compilador que colecciona retazos de cultura, tradición y pueblo, y los rescata como semilla fecunda de una verdad ancestral, cuidadosamente conservada en las formas tradicionales de vida pero en grave riesgo de desaparición.

No obstante, el apremio del rescate tuvo consecuencias inesperadas. La tarea tuvo más que ver con la recolección de elementos culturales a propósito del «culto del pueblo» que con el avance en el conocimiento cuidadoso de las culturas. Se propició una confluencia artificiosa de criterios para clasificar y evaluar aquellos elementos acreedores de una naturaleza «tradicional» y «popular», dando lugar a estereotipos culturales que generalmente reflejaban mejor el ideal romántico del paraíso rural, que la realidad social y cultural que le daban cuerpo. Lo que la búsqueda de la «cultura popular» significó de hecho no fue su descubrimiento, sino la consagración del canon bucólico. Con ello, el imperativo de conservación de las «culturas» convertía a 1as tradiciones» en vestigios de sí mismas, en elementos cosificados que adquieren sentidos inéditos, distintos de los que tenían antes de pasar a ser «tradicionales» por el bautismo del folklore. Y así nacía el moderno discurso sobre la Tradición con su peculiar uso salvífico bajo el patronazgo de sus gestores.

En el primero de los tres ensayos que componen la obra, el autor repasa diferentes aportaciones al debate sobre la cultura. El nacimiento de la «cultura popular» se sitúa precisamente en la aplicación de las inquietudes universalistas por la cultura en general a los contextos locales cercanos. El interés por lo originario y lo auténtico se fue centrando cada vez más en el «saber popular». Inspirándose en un texto de Herodoto, Díaz propone una parábola que le sirve para trazar la línea que sigue esta búsqueda. Desde Tylor, pasando por la idea de civilización de Kroeber, el continuo folk/urbano de Redfield, la analogía de Roman Jakobson (lengua: cultura: habla: cultura popular), etc., el autor llega a Hobsbawm y acaba con una crítica a los conceptos de cultura presentes en estos modelos. Contra una concepción estática y sustancialista, el autor propone una concepción dinámica de la cultura, caracterizada no por la tradición, sino por una variedad de tradiciones, a veces contradictorias entre sí, una cultura viva y en constante actualización.

A pesar de defender esta perspectiva de la cultura, la propuesta parece naufragar en el esquema que ensaya el autor siguiendo a Redfield. Se trata de una contradicción interna del modelo explicativo, pues al analizar la cultura como fruto de las relaciones entre Gran Tradición y Pequeña Tradición el resultado apunta hacia la «producción» de lo menor (como objeto) por lo mayor (como sujeto efectivo de la lógica cultural), y no hacia la concepción dinámica de una cultura popular plural.

En el segundo capítulo Luís Díaz aborda la constitución del canon de lo popular, especialmente con la revisión de las obras de Juan y Ramón Menéndez Pidal. Lo que se plantea es la cuestión de cómo aprehender lo popular, cómo acercarse a la realidad de la cultura. Este problema deriva en el debate sobre la autenticidad de las fuentes. Díaz propone que las fuentes sufren una suerte de «autentificación» por parte de los recopiladores y estudiosos, que parten acríticamente de unos criterios de selección (antigüedad, origen rural, transmisión oral, carácter típico y autóctono, etc.) que proceden del ideal romántico y lo ratifican.

El tercer ensayo es una aproximación a los investigadores de campo que con muy diversas actitudes, propósitos y recursos, se han interesado por la cultura en/de nuestro país. El autor llama la atención sobre las problemáticas relaciones entre estos investigadores. A propósito de la cuestión de la autenticidad, los etnógrafos, folkloristas, tradicionalistas, filólogos... se han venido disputando desde la pertinencia de su origen o la legitimidad de sus metodologías, hasta el mismo terreno de trabajo o los informantes. En este tercer capítulo podemos encontrar aplicados al caso español (y castellano leonés en especial) las reflexiones generales introducidas en los dos ensayos anteriores. Díaz 
destaca la obra de Julio Caro y su participación en el debate con otros «especialistas» sobre las fuentes y la naturaleza de la cultura, las tradiciones y lo popular en nuestro país. Repasa los principales autores que han desarrollado estos temas en la Antropología española: Caro Baroja, Pitt-Rivers, Esteva Fabregat, Kenny, Tax Freeman.

Por último Luís Díaz G. Viana recupera los temas principales de la obra para ofrecer una conclusión unitaria sobre los tres ensayos. La cultura popular se inventa como utopía del pasado en el marco de la desconfianza por el progreso. El autor encuentra que «la sensación angustiosa de estar asistiendo al derrumbamiento del mundo» (p. 111) conduce a un subjetivismo que reivindica lo pro- pio, el conocimiento local, la fe, lo mítico... como modos de rescatar la voz a los que no han sido escuchados y dotar al Pueblo de un alma, una esencia. Oportunamente Díaz señala para acabar: Pare ce obvio que si cierto discurso romántico, conser vador e interesado sobre lo popular, sigue teniendo tanta aceptación en determinados lugares y ámbi tos [ ... 1 es porque no han cambiado lo bastante las condiciones en que se produjo: la sensación por parte de algunas clases medias de hallarse desarraigadas, si no desalojadas en el nuevo orden social, la inseguridad y desconfianza ante el futu ro, la necesidad de una nueva fe (p. 113).

Mónica Cornejo Valle 